

\title{
IMPERFECT MIMICRY AND THE LIMITS OF NATURAL SELECTION
}

\author{
David W. KikUChI \\ Department of Biology, University of North Carolina \\ Chapel Hill, North Carolina 27599-3280 USA \\ E-MAIL:DKIKUCHI@LIVE.UNC.EDU \\ David W. Pfennig \\ Department of Biology, University of North Carolina \\ Chapel Hill, North Carolina 27599-3280 USA \\ E-MAIL: DPFENNIG@UNC.EDU
}

KEYWORDS

Batesian mimicry, Müllerian mimicry, signal detection, cognition, complexity

\begin{abstract}
Mimicry-when one organism (the mimic) evolves a phenotypic resemblance to another (the model) due to selective benefits - is widely used to illustrate natural selection's power to generate adaptations. However, many putative mimics resemble their models imprecisely, and such imperfect mimicry represents a specific challenge to mimicry theory and a general one to evolutionary theory. Here, we discuss 11 nonmutually exclusive hypotheses for imperfect mimicry. We group these hypotheses according to whether imperfect mimicry reflects: an artifact of human perception, which is not shared by any naturally occurring predators and therefore is not truly an instance of imperfect mimicry; genetic, developmental, or time-lag constraints, which (temporarily) prevent a response to selection for perfect mimicry; relaxed selection, where imperfect mimicry is as adaptive as perfect mimicry; or tradeoffs, where imperfect mimicry is (locally) more adaptive than perfect mimicry. We find that the relaxed selection hypothesis has garnered the most support. However, because only a few study systems have thus far been comprehensively evaluated, the relative contributions of the various hypotheses toward explaining the evolution of imperfect mimicry remain unclear. Ultimately, clarifying why imperfect mimicry exists should provide critical insights into the limits of natural selection in producing complex adaptations.
\end{abstract}

\section{INTRODUCTION}

$\mathrm{N}^{\prime}$ ATURAL selection's power to produce remarkable adaptations is beautifully exemplified by mimicry, which occurs when one organism (the mimic) converges on phenotypic features of another (the model) because of the selective benefits of sharing such a resemblance (see reviews in Wickler 1968; Edmunds 1974; Endler 1981; Waldbauer 1988; Malcolm 1990; Mallet and Joron

The Quarterly Review of Biology, December 2013, Vol. 88, No. 4

Copyright (C) 2013 by The University of Chicago Press. All rights reserved.

0033-5770/2013/8804-0002\$15.00 
1999; Ruxton et al. 2004; Forbes 2009; Kikuchi and Pfennig 2012a; Grim 2013). It has long been assumed that mimics should always experience selection to resemble their models closely (Ruxton et al. 2004), yet it has become increasingly clear that many resemble their models less precisely than biologists have expected them to (Sherratt 2002; Gilbert 2005). For instance, many species of harmless Neotropical snakes resemble highly venomous coral snakes (Brodie and Brodie 2004). Although some species are amazingly similar to coral snakes (Greene and McDiarmid 2005), most species have only a coarse resemblance (Savage and Slowinski 1992). The existence of such imperfect mimicry poses a central challenge to traditional theory (Edmunds 2000; Sherratt 2002; Ruxton et al. 2004:159-161).

Although numerous hypotheses have been put forth to explain imperfect mimicry (Penney et al. 2012; Pfennig and Kikuchi 2012), the relationships among these hypotheses, and their mutually exclusive predictions, have not been explored comprehensively. Moreover, most of these hypotheses have been tested unevenly, with some having been tested rigorously and others having received little, if any, empirical attention (Penney et al. 2012; Pfennig and Kikuchi 2012). In this review, we seek to classify and clarify the various hypotheses that have been advanced for imprecise mimicry's persistence. We also describe the empirical evidence in support of the various hypotheses to point out the ones that appear to have broad relevance and those that require more investigation. Finally, we provide a roadmap for future research into the evolution of imperfect mimicry.

We have defined "mimicry" as occurring when one organism converges on phenotypic features of another because of the selective benefits of sharing a resemblance, although in many cases commonly assumed to be mimicry, selective benefits have not been directly tested. This definition implies that the evolved resemblance must involve signals. Signals can be thought of as an "act or structure that alters the behaviour of another organism, which evolved because of that effect, and which is effective because the receiver's response has also evolved" (Maynard-Smith and Harper 2003:15; see also Bradbury and Vehrencamp 2011). Signals are the basis of both mimicry and "aposematism" (when a dangerous species evolves a phenotype that accurately warns others of the danger). Mimicry occurs when a signal borne by one organism (the model) to communicate some quality to others (the receivers), is copied by another organism (the mimic) to convey the same message to the same receivers, whether it is honest or not. This relationship may involve three or more species (e.g., multiple prey species and their predators), two species (as is sometimes the case in aggressive mimicry), or even take place within a single species (as occurs in reproductive mimicry). Signals may travel via any media, including visual, auditory, and chemical; they may also be multimodal and include more than one of those senses.

The two best-known forms of mimicry are: "Batesian mimicry" (Bates 1862), which occurs when an edible species (the mimic) evolves to resemble a conspicuous, inedible species (the model), thereby gaining protection from predation; and "Müllerian mimicry" (Müller 1879), which occurs when multiple defended species (co-mimics) converge on the same warning signal, thereby sharing the cost of educating predators about their unpalatability. Although there are other types of mimicry, such as aggressive mimicry and reproductive mimicry (where mimicry evolves in response to sexual selection; Vane-Wright 1976; Endler 1981; Kikuchi and Pfennig 2012a), we will not dwell on specific types of mimicry except when a particular hypothesis requires that we do so.

With this background in mind, we now turn to hypotheses that have been advanced to explain the evolution of imperfect mimicry.

\section{Hypotheses for IMPERFECT Mimicry's Existence and Persistence}

Many explanations have been proposed to explain imperfect mimicry, some more plausible than others (Ruxton et al. 2004). In this section, we discuss 11 nonmutually exclusive hypotheses. As summarized in Table 1, each hypothesis can be grouped into one of four categories, depending upon whether the hy- 
TABLE 1

A classification scheme for 11 nonmutually exclusive hypotheses on the evolution of imperfect mimicry

\begin{tabular}{|c|c|c|c|c|}
\hline \multirow[b]{2}{*}{ Hypothesis } & \multicolumn{4}{|c|}{ Imperfect mimicry reflects . . . } \\
\hline & $\begin{array}{c}\text { an artifact of human } \\
\text { perception not } \\
\text { shared by natural } \\
\text { signal receivers }\end{array}$ & $\begin{array}{c}\text { genetic or } \\
\text { developmental } \\
\text { constraints, which } \\
\text { (temporarily) } \\
\text { limit a response } \\
\text { to selection }\end{array}$ & $\begin{array}{c}\text { relaxed selection, } \\
\text { where imperfect } \\
\text { mimics are as fit } \\
\text { as perfect mimics }\end{array}$ & $\begin{array}{c}\text { an (at } \\
\text { least locally) } \\
\text { adaptive peak } \\
\end{array}$ \\
\hline Eye-of-the-beholder & $\mathrm{x}$ & & & \\
\hline Developmental constraints & & $\mathrm{x}$ & & \\
\hline Chase-away & & $\mathrm{x}$ & & \\
\hline Relaxed selection & & & $\mathrm{x}$ & \\
\hline Mimetic Breakdown & & & & $\mathrm{x}$ \\
\hline Perceptual exploitation & & & & $\mathrm{x}$ \\
\hline Satyric mimicry & & & & $\mathrm{X}$ \\
\hline Multiple models & & & & $\mathrm{x}$ \\
\hline Multiple predators & & & & $\mathrm{x}$ \\
\hline Kin selection & & & & $\mathrm{X}$ \\
\hline Character displacement & & & & $\mathrm{x}$ \\
\hline
\end{tabular}

pothesis posits that putative cases of imperfect mimicry reflect: an artifact of human perception that does not pertain to mimicry; genetic or developmental constraints, which prevent a response to selection for better mimicry; relaxed selection, where imperfect mimicry is as adaptive as perfect mimicry; or tradeoffs, where imperfect mimicry is locally more adaptive than perfect mimicry (for general models of how tradeoff costs can lead to imperfect mimicry, see Servedio and Lande 2003; Holen and Johnstone 2004). Below, we describe each hypothesis in detail. In Table 2, we provide a brief summary of the hypotheses.

\section{EYE-OF-THE-BEHOLDER HYPOTHESIS}

This hypothesis suggests that some cases of imperfect mimicry are not mimicry at all (Cuthill and Bennett 1993; Dittrich et al. 1993). Instead, human perception detects imperfections that natural signal receivers cannot. Therefore, "imperfect" mimicry does not represent a challenge to natural selection because the "imperfections" are not relevant for the intended signal receivers. Real organisms have an almost limitless number of phenotypic dimensions into which they can be decomposed, so it is unsurprising that some cases of imperfect mimicry might be attrib- utable to differences between the dimensions of organisms that humans notice versus the ones their ecologically relevant signal receivers pay attention to.

\section{DEVELOPMENTAL AND GENETIC CONSTRAINTS HYPOTHESIS}

Rather than being an artifact of human perception, as in the eye-of-the-beholder hypothesis above, imperfect mimicry may reflect a constraint on signal production, which (at least temporarily) prevents a response to selection for better mimicry. For example, a population of imprecise mimics may lack the genetic variation needed to evolve a closer match to the model (in the case of Batesian mimicry) or co-mimics (in the case of Müllerian mimicry). It is important to point out that most constraints can likely be overcome, given enough time and sufficiently strong selection (Maynard Smith et al. 1985). For this reason, constraints probably do not offer a universal explanation for imprecise mimicry.

\section{CHASE-AWAY HYPOTHESIS}

This hypothesis, like the constraints hypothesis above, assumes that imperfect Batesian mimicry reflects an inability to (at least 
TABLE 2

Summary of 11 hypotheses for imperfect mimicry and their critical predictions

\begin{tabular}{|c|c|c|c|}
\hline Hypothesis & Mechanism & Critical predictions & Key references \\
\hline Eye-of-the-beholder & $\begin{array}{l}\text { Imperfect mimicry is an } \\
\text { anthropocentric projection; real } \\
\text { predators do not distinguish } \\
\text { between models and "imperfect" } \\
\text { mimics }\end{array}$ & $\begin{array}{l}\text { Humans score model-mimic } \\
\text { similarity differently from } \\
\text { predators (under similar } \\
\text { conditions) }\end{array}$ & $\begin{array}{l}\text { Cuthill and Bennett (1993); } \\
\text { Dittrich et al. (1993) }\end{array}$ \\
\hline $\begin{array}{l}\text { Developmental and } \\
\text { genetic } \\
\text { constraints }\end{array}$ & $\begin{array}{l}\text { Production of better mimetic signals } \\
\text { is constrained by an intrinsic } \\
\text { inability to produce them }\end{array}$ & $\begin{array}{l}\text { Imperfect mimics are less fit than } \\
\text { perfect mimics; proximate } \\
\text { mechanisms reveal constraints }\end{array}$ & Maynard-Smith et al. (1985) \\
\hline Chase-away & $\begin{array}{l}\text { Models evolve away from their } \\
\text { Batesian mimics; time-lag } \\
\text { prevents immediate mimic } \\
\text { response }\end{array}$ & $\begin{array}{l}\text { Similar to developmental and } \\
\text { genetic constraints; plus } \\
\text { evolutionary change in model } \\
\text { phenotype due to negative } \\
\text { fitness consequences of } \\
\text { Batesian mimics }\end{array}$ & $\begin{array}{l}\text { Nur (1970); McGuire et al. } \\
\text { 2006); Franks et al. } \\
\text { (2009) }\end{array}$ \\
\hline Relaxed selection & $\begin{array}{l}\text { Mimics are under little selection to } \\
\text { evolve better mimicry because of } \\
\text { the risks of accidentally attacking } \\
\text { a model }\end{array}$ & $\begin{array}{l}\text { Mimetic precision correlates } \\
\text { positively with relative mimic } \\
\text { abundance/benefits and } \\
\text { negatively with alternative prey }\end{array}$ & $\begin{array}{l}\text { Schmidt (1958); Duncan } \\
\text { and Sheppard (1965); } \\
\text { Sherratt (2002); Penney } \\
\text { et al. (2012) }\end{array}$ \\
\hline $\begin{array}{l}\text { Mimetic } \\
\text { breakdown }\end{array}$ & $\begin{array}{l}\text { Mimicry is no longer advantageous } \\
\text { due to a paucity of models }\end{array}$ & $\begin{array}{l}\text { Imperfect mimicry is favored } \\
\text { relative to perfect mimicry in } \\
\text { the absence of models }\end{array}$ & $\begin{array}{l}\text { Sheppard (1959); Brower } \\
\text { (1960); Pfennig and } \\
\text { Mullen (2010) }\end{array}$ \\
\hline $\begin{array}{l}\text { Perceptual } \\
\quad \text { exploitation }\end{array}$ & $\begin{array}{l}\text { Signal receivers have a bias toward } \\
\text { signals that are displaced from } \\
\text { the model's signal }\end{array}$ & $\begin{array}{l}\text { Imperfect mimics elicit a stronger } \\
\text { response from signal receivers } \\
\text { than their models do }\end{array}$ & $\begin{array}{l}\text { Vereecken and Schiestl } \\
\text { (2008) }\end{array}$ \\
\hline Satyric mimicry & $\begin{array}{l}\text { Imperfect mimics that blend some } \\
\text { components of the model's signal } \\
\text { with irrelevant stimuli confuse } \\
\text { signal receivers, resulting in } \\
\text { better protection than imperfect } \\
\text { mimics that do not }\end{array}$ & $\begin{array}{l}\text { Components of the aposematic } \\
\text { signal elicit greater receiver } \\
\text { avoidance/latency to respond } \\
\text { when presented with irrelevant } \\
\text { stimuli than without }\end{array}$ & Howse and Allen (1994) \\
\hline Multiple models & $\begin{array}{l}\text { When multiple models exist, mimics } \\
\text { adopt an intermediate phenotype } \\
\text { between them to receive } \\
\text { protection from more than one } \\
\text { of them }\end{array}$ & $\begin{array}{l}\text { Imperfect mimics are phenotypic } \\
\text { intermediates between models } \\
\text { and have higher fitness than } \\
\text { mimics more closely } \\
\text { resembling any one }\end{array}$ & $\begin{array}{l}\text { Edmunds (2000); Sherratt } \\
\quad(2002)\end{array}$ \\
\hline Multiple predators & $\begin{array}{l}\text { Imperfect mimics are a compromise } \\
\text { between duping generalist } \\
\text { predators and avoiding specialist } \\
\text { predators }\end{array}$ & $\begin{array}{l}\text { Opposing selective pressures on } \\
\text { mimetic phenotype by } \\
\text { generalist and specialist } \\
\text { predators }\end{array}$ & Pekar et al. (2011) \\
\hline Kin selection & $\begin{array}{l}\text { Imperfect mimicry persists because } \\
\text { it lowers overall attack rates on a } \\
\text { population of related mimics }\end{array}$ & $\begin{array}{l}\text { Mimetic precision is inversely } \\
\text { correlated with relatedness of } \\
\text { mimetic populations and } \\
\text { mimic abundance }\end{array}$ & $\begin{array}{l}\text { Johnstone (2002); Penney } \\
\text { et al. (2012) }\end{array}$ \\
\hline $\begin{array}{l}\text { Character } \\
\text { displacement }\end{array}$ & $\begin{array}{l}\text { Competition between mimics and } \\
\text { their models and co-mimics } \\
\text { displaces phenotypic optimum } \\
\text { away from perfect mimicry }\end{array}$ & $\begin{array}{l}\text { Mimics and their models/ } \\
\text { co-mimics overlap in resource } \\
\text { use and/or reproductive trait } \\
\text { space; competitively mediated } \\
\text { selection disfavors more } \\
\text { precise mimics }\end{array}$ & Pfennig and Kikuchi (2012) \\
\hline
\end{tabular}


temporarily) respond to selection for perfect mimicry. According to this hypothesis, imperfect Batesian mimics could evolve to become better mimics, but their models are also under selection to evolve away from them to avoid the fitness cost of having a "parasitic" mimic. As a result of such "chaseaway" selection, mimics lag behind models in phenotypic evolution because models evolve away from mimics as soon as they are approached too closely in signal space. Essentially, when we observe instances of imperfect mimicry, we see the outcome of an evolutionary arms race between mimic and model, which the model has won (as least temporarily). In these cases, time lags (between when the model moves away from the mimic in phenotypic space and when the mimic can evolve the new phenotype of the model) lead to imperfect mimicry.

Chase-away is predicted to occur by many theoretical models (e.g., Oaten et al. 1975; Holland and Rice 1998; Holmgren and Enqvist 1999; Franks and Noble 2004; Franks et al. 2009). However, mimics should generally experience stronger selection to match their models than models do to evolve away from their mimics. This is because changes in a mimic's phenotype that make it more like its model will often provide a selective advantage (Ruxton et al. 2004). Models, on the other hand, will generally receive less benefit from changing their phenotype because rare mutants from the model population would be poorly protected and therefore risk increased predation (Nur 1970). Consequently, even in the presence of chase-away selection, models may generally not evolve to escape their mimics.

\section{RELAXED SELECTION HYPOTHESIS}

The relaxed selection hypothesis assumes that imperfect mimicry reflects a lack of selection, where some imperfect mimics have fitness equal to that of the model because predators do not discriminate between the two. This hypothesis is predicated on the notion that, when models and mimics share signal dimensions, it is impossible for signal receivers to discriminate them perfectly. This occurs because the strength of selection for better resemblance is relaxed as the mimic

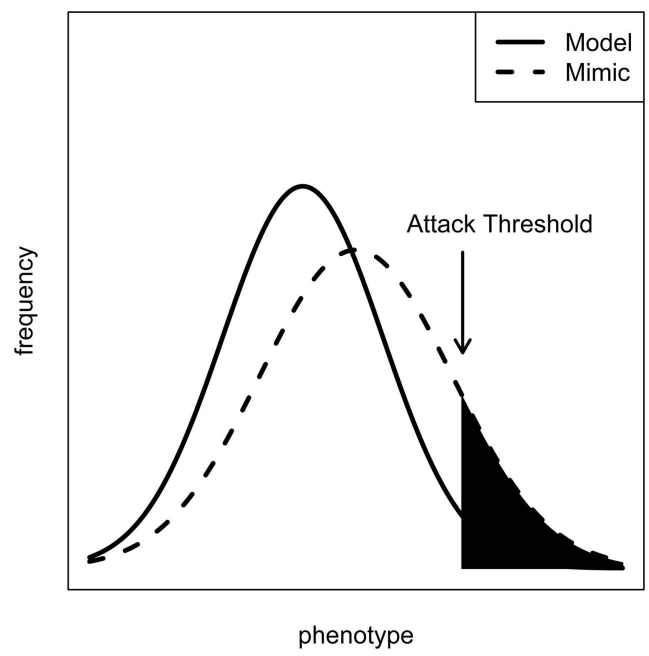

Figure 1. Threshold For Selecting Imperfect Mimics When Their Phenotypic Distribution Differs From That of THeir MODELS

The signal receiver should choose all organisms encountered to the right of the threshold (shaded area), as they offer an average positive return.

evolves toward the model's phenotype (Duncan and Sheppard 1965; Sherratt 2001, 2002). Signal receivers must balance correctly accepting mimics against mistakenly accepting models, a situation analogous to managing Type I and II error in statistics. There may be actual phenotypic overlap between models and mimics, or noise in the signal receiver's senses.

To explain this phenomenon, many mathematical models of selection in mimicry have used signal detection theory (e.g., Oaten et al. 1975; Getty 1985; Sherratt 2001, 2002), which is designed to optimize correct responses to signals and minimize errors. Results show that receivers should select a phenotypic threshold that guarantees them a positive average payoff if they accept all signalers that fall on one side of that threshold (Figure 1). The position of the threshold depends on the costs of accepting a model, the benefits of accepting a mimic, and the relative abundance of the two (as well as alternate, nonmimetic signalers; Dill 1975; Sherratt and Beatty 2003; Lindström et al. 2004). When models are very aversive/abun- 


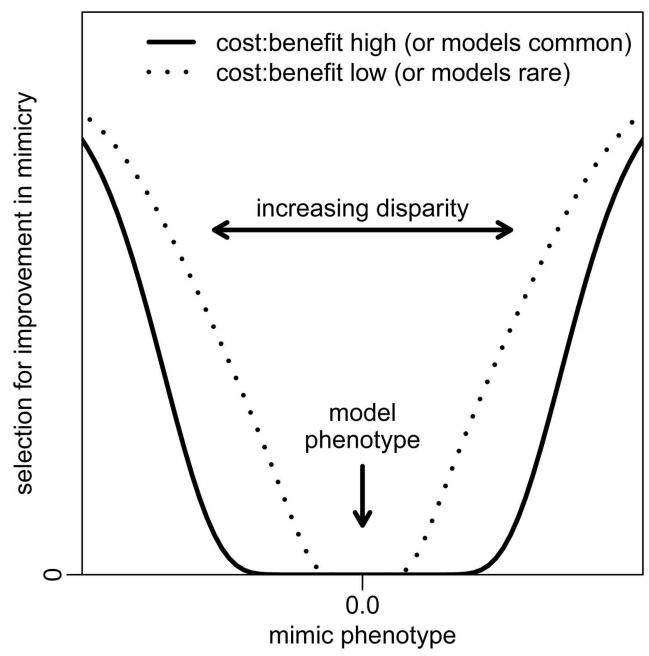

Figure 2. Variation in the Strength of Selection For Mimicry (Not Relative Fitness) with Respect to Mimetic Phenotype

The phenotype of the model is marked with an arrow at 0.0 , so phenotypes closer to either end of the $\mathrm{x}$-axis resemble the model less. Mimics more distant from their model in phenotype are under stronger selection to improve mimicry than ones which already resemble their models closely (i.e., selection is nonlinear). Furthermore, the shape of the curve changes with different cost:benefit ratios for attacking models and mimics (dotted line). Relatively less costly/abundant models create a smaller area of phenotypic space around them in which mimics are under little selection to improve. Adapted from Sherratt (2002).

dant, mimics are relatively unrewarding/rare, or-sometimes-when models and mimics appear to overlap more in phenotype, a smaller percentage of the mimic population is attacked, and therefore selection for mimicry is weaker. The result is that there is often a wide range of phenotypes near the phenotype of the model that have nearly equal fitness (Figure 2).

The relaxed selection hypothesis yields clear predictions based on the strength of selection as mimics approach models in phenotypic space and as the cost:benefit ratio of attacking models and mimics changes. The strength of selection for better mimicry decreases as the mimic approaches the model in phenotype; mimetic precision decreases with model abundance and costliness (such as toxicity, aggression, or handling time), and nonaversive alternative signalers; and it increases with the mimic's relative abundance and benefits (for example, caloric reward).

\section{MIMETIC BREAKDOWN HYPOTHESIS}

In the remaining seven hypotheses, imperfect mimicry is assumed to arise from some sort of tradeoff, where imperfect mimicry is (locally) more adaptive than perfect mimicry. Under the first of these hypotheses-the mimetic breakdown hypothesisimprecise mimicry reflects an evolutionary compromise between gene flow on the one hand and selection on the other.

Indeed, a classic explanation for a mismatch between mimics and their models is that mimicry no longer serves any benefit and, consequently, precise mimicry has been degraded by natural selection (Brower 1960). Such mimetic breakdown should happen when mimics occur in areas where their model is rare or absent. Batesian mimicry theory generally predicts that mimics should occur only in areas where their model occurs (i.e., sympatry; Ruxton et al. 2004). This is because protection from predation should break down where the model is absent. Many mimics violate this prediction and also occur in areas where their model is absent (i.e., allopatry; Pfennig and Mullen 2010).

Mimics that occur in both sympatry and allopatry with their model should experience strong divergent selection. On the one hand, selection should always favor the maintenance, and even enhancement, of the mimetic phenotype in sympatry. On the other hand, selection should favor the breakdown of this phenotype in allopatry, because mimics (like their models) are often conspicuous (Ruxton et al. 2004). Allopatric mimics should generally experience increased predation pressure relative to less noticeable types. If such selection is strong, then allopatric mimics should evolve less conspicuous (nonmimetic) phenotypes. Thus, imprecise mimics may be in the process of evolving nonmimetic phenotypes, have imperfect mimetic phenotypes that are to some degree maintained by gene flow (Harper and Pfennig 2008), or retain their mimetic coloration for 
an alternative reason such as flicker-fusion coloration (Pough 1976) or sexual selection. Under this hypothesis, an imperfect mimic would have higher fitness than a perfect mimic in the allopatric environment. We should note, however, that some populations of allopatric mimics may be under selection by predators migrating from sympatry, and that under those circumstances this hypothesis would not be expected to apply.

\section{PERCEPTUAL EXPLOITATION HYPOTHESIS}

Under this hypothesis, mimics exploit an innate perceptual bias in signal receivers that is shifted away from the model's signal. Such "sensory drive" hypotheses are often invoked to explain the evolution of sexual signals (e.g., Basolo 1990; Ryan et al. 1990), but seldom to explain imperfect mimicry. This is because ecological conditions that select for receivers that respond most strongly to something other than the model's signal may be rare (given some cost of producing and bearing signals, models are expected to evolve signals that elicit the strongest possible response from the receiver).

\section{SATYRIC MIMICRY HYPOTHESIS}

The satyric mimicry hypothesis proposes that, while some mimics may be good enough that they cannot be distinguished from the model, others benefit from expressing components of aposematic signals in inappropriate contexts (e.g., a wasp's stripes on a fly's body). In doing so, these individuals confuse predators long enough to allow the individual to escape (Howse and Allen 1994). Howse and Allen (1994:113) further elaborated their theory to predict, "opposing features will tend to be favoured by natural selection so that a high degree of ambiguity is achieved." Thus, imperfect mimics with a mixture of traits from the model and alternative prey should have higher fitness than imperfect mimics that resemble the model more, but are still distinguishable.

\section{MULTIPLE MODELS HYPOTHESIS}

Edmunds (2000) hypothesized that, in mimics that occur over a wide geographical area that contain multiple models, selection will favor those individuals that imprecisely resemble many different species of models over those individuals that precisely resemble only one species of model. In such circumstances, Edmunds (2000) showed that generalist mimics have higher population sizes than specialist mimics of single models. Sherratt (2002) reexamined this hypothesis in a mathematical framework where he assumed that model and mimic phenotypes vary continuously and that predators use signal detection theory to set optimal thresholds for attacking prey. He found that when multiple sympatric models exist, mimics evolve to mimic one of them or adopt an intermediate phenotype. Which result occurs depends on whether or not models are similar enough to confuse predators. When models are allopatric from one another, mimics evolve intermediate phenotypes, although their intermediate phenotype should be weighted toward the less defended or numerous model.

\section{MULTIPLE PREDATORS HYPOTHESIS}

Pekár et al. (2011) proposed that Batesian mimics may be exposed to some predators that respond to mimicry according to Bates' original theory (1862), but that they may, as a consequence, suffer increased predation by specialist predators of their models (Pekár et al. 2011). Therefore, the optimal mimetic phenotype represents a compromise between duping generalist predators and being able to escape from specialist ones.

\section{KIN SELECTION HYPOTHESIS}

According to this hypothesis, Batesian mimics pay an inclusive fitness cost of improving mimicry, because doing so increases overall attacks on a population that includes close kin (Johnstone 2002). When models are sufficiently rare and/or weakly aversive, predators should always attack prey that perfectly resemble them, because the odds of encountering a beneficial mimic make such behavior worthwhile (Oaten et al. 1975). With such a weak and outnumbered model, the population of mimics will actually benefit from lower attack rates when it is, on average, imperfect. This is because predators will focus their attacks on the most imprecise mimics in 
the population rather than the whole population, so at least the better mimics in the population will benefit from mimicry. The better mimics will experience individual (direct) selection for improved mimicry, but if the population is related enough, the negative indirect effects of increased predation on the whole population may cancel out direct fitness benefits, leading to a stable equilibrium of imperfect mimicry (Johnstone 2002).

\section{CHARACTER DISPLACEMENT HYPOTHESIS}

According to this hypothesis, imprecise mimicry represents an evolutionary compromise between predator-mediated selection favoring phenotypic convergence (i.e., precise mimicry) on the one hand and competitively mediated selection favoring phenotypic divergence (i.e., imprecise mimicry) on the other (Pfennig and Kikuchi 2012). In other words, imprecise mimicry is a manifestation of "character displacement" - trait evolution that arises as an adaptive response to resource competition or deleterious reproductive interactions between species (sensu Brown and Wilson 1956; see also Grant 1972; Schluter 2000; Dayan and Simberloff 2005; Grether et al. 2009; Pfennig and Pfennig 2009, 2012).

To understand how this hypothesis works, consider that for mimicry to be an effective deterrent to predation, mimics and their models (in the case of Batesian mimicry) or co-mimics (in the case of Müllerian mimicry) should not only be phenotypically similar to each other, but they should also occur together in the same location and at the same time (Beatty and Franks 2012). Yet co-occurring, phenotypically similar species often compete with each other for resources, successful reproduction, or both (here, "competition" refers to any direct or indirect interaction between species or populations that reduces access to vital resources or successful reproductive opportunities and that is therefore deleterious - on average - to both parties; see Pfennig and Pfennig 2012). As an adaptive response to minimize such costly interactions, competitively mediated selection favors individuals that differ from their heterospecific competitors (reviewed in Schluter 2000; Dayan and Simberloff 2005; Pfennig and Pfennig 2009, 2012). Conse- quently, interacting species diverge phenotypically through the process known as character displacement. Such divergence between mimics and their models/co-mimics thereby results in imperfect mimicry (Pfennig and Kikuchi 2012).

Imprecise mimicry may arise through either reproductive or ecological character displacement. Reproductive character displacement may generate imperfect mimicry if signals aimed at potential predators also target prospective mates (Estrada and Jiggins 2008). Such shared signals may increase the risk that mimics and their models/co-mimics will engage in costly hybridization with each other or interfere with each other's ability to identify high-quality mates. In such situations, selection may favor reproductive character displacement as a means of reducing costly reproductive interactions between mimics and their models/ co-mimics.

Ecological character displacement may generate imprecise mimicry if aposematic/ mimetic signals aimed at potential predators are in some way environmentally dependent, such that their production requires some limited resource (e.g., a food item or a particular habitat). In such cases, if mimics compete with their models/co-mimics for this resource, then ecological character displacement leads to a change in diet. Consequently, the production of mimetic phenotypes may be affected also, possibly even leading to the evolution of imprecise mimicry.

Finally, competition for space may also promote imprecise mimicry through relaxed selection for precise mimicry. For instance, if mimics and their models/co-mimics compete for a particular microhabitat, ecological character displacement may promote a habitat shift. If the mimetic species is forced into a microhabitat not occupied by its model, then selection for precise mimicry may be relaxed, leading instead to imprecise mimicry (recall from above that for mimicry to be an effective deterrent to predation, mimics and their models/co-mimics should occur together).

Regardless of whether reproductive or ecological character displacement is responsible, this hypothesis generally predicts that imprecise mimicry should evolve whenever 
predator-mediated selection is weak relative to competitively mediated selection (Pfennig and Kikuchi 2012).

\section{EMPIRICAL Hypothesis Support}

EYE-OF-THE-BEHOLDER HYPOTHESIS

One of the first studies to explicitly address the "eye-of-the-beholder" hypothesis was that of Dittrich et al. (1993), who trained pigeons to avoid images of wasps but to attack their hoverfly mimics. They used a morphometric approach to describe objective similarity between hoverflies and their models, and found that pigeon attack rates declined sigmoidally with resemblance to the wasps so that even a $50 \%$ objective match to the model conferred the full benefit of mimicry. The authors concluded that apparently poor mimics to human eyes might be quite good from the perspective of other animals. Cuthill and Bennett (1993) suggested that the mechanistic explanation for the sigmoid curve might be that the images used were optimized for human rather than avian vision, so birds could not use all of the information that would normally be available to them.

This hypothesis may not, in fact, be sufficient to explain imperfect mimicry in the wasp-hoverfly system in which it was first suggested. Penney et al. (2012) found that humans rank the similarity between wasps and hoverflies more like pigeons than an objective morphometric analysis. Indeed, pigeons used only some of the potentially informative traits on the hoverflies to discriminate them from wasps (Bain et al. 2007). Thus, in this instance, imperfect mimicry is probably not entirely the result of a discrepancy between what humans intuit a good mimic should look like and what is required to fool a predator.

Another example of how human perspective can explain an apparent case of imperfect mimicry can be found among coral snakes and their mimics, scarlet kingsnakes. In the southeastern United States, venomous coral snakes have red, yellow, and black rings arranged in the order Y-R-Y-B. Nonvenomous scarlet kingsnakes have the same three colors arranged into rings with a different order: Y-B-R-B. The relative proportions of red:black are under strong selection (Harper and Pfennig 2007), as is the general ringed appearance (Pfennig et al. 2001), but the order of the colored rings is probably not (Kikuchi and Pfennig 2010a). It seems likely that while colored rings with a certain proportion of red:black constitute a warning signal, the order in which the rings develop is an arbitrary byproduct of their evolution. This case of imperfect mimicry can indeed be attributed to humans projecting their own perception onto a system, which emphasizes the importance of correctly identifying a model's actual signal.

\section{DEVELOPMENTAL AND GENETIC} CONSTRAINTS HYPOTHESIS

Presently, few studies have thus far examined the proximate bases of mimetic phenotypes, so it is unclear to what degree imperfect mimicry reflects an underlying constraint on signal production. Of those studies that have looked into proximate mechanisms, models and mimics appear to use at least some of the same genes and/or physiological pathways to produce shared signals (Ford 1953; Joron et al. 2011; Heliconius Genome Consortium 2012; Kikuchi and Pfennig 2012b; Martin et al. 2012). An exception to this trend are certain unrewarding orchids, which attract male bees to pollinate them by mimicking the exact chemical compounds exuded by female bees (Vereeken and Schiestl 2008). In this case, the orchids produce their pheromones by using enzymes that are unrelated to those found in their pollinators (Schlüter et al. 2011). Generally, species that share the same proximate mechanisms used to produce aposematic signals may be more prone to evolve precise mimicry. Yet, as the orchid example above illustrates, sharing similar proximate mechanisms is not a necessity for precise mimicry.

\section{CHASE-AWAY HYPOTHESIS}

An empirical study with human subjects selecting between two species of computergenerated prey was able to produce chaseaway, but the difference between models and mimics was quite small relative to the range 
of potential phenotypic difference (McGuire et al. 2006). We are unaware of any study that adequately demonstrates a model evolving away from its mimic in nature, or resultant imperfect mimicry.

\section{RELAXED SELECTION HYPOTHESIS}

All of the predictions of this hypothesis have been confirmed in empirical systems. Many studies have documented selective surfaces that correspond to those outlined in Figure 2: animals or humans trained to respond to artificial prey (or flowers, in the case of plants) reduce attack rates nonlinearly as mimics approach models in phenotype (Schmidt 1958; Duncan and Sheppard 1965; Ford 1971; Caley and Schluter 2003; Lynn et al. 2005; McGuire et al. 2006). Furthermore, changing the relative abundance of models and mimics alters the amount of phenotypic space in which imperfect mimics receive protection: the precision of coral snake mimicry by scarlet kingsnakes (and selection for better mimicry) increases across the kingsnake's range as the abundance of coral snakes decreases (Harper and Pfennig 2007; Kikuchi and Pfennig 2010b), and the mimetic precision of andromorphs (malemimicking females) increases with the proportion of andromorphs:males in damselfly populations (females resemble males to escape sexual harassment; Iserbyt et al. 2011). Changing the cost:benefit ratio of attacking models and mimics also changes the phenotypic space in which imperfect mimics are protected: artificial Batesian mimicry systems show that mimics are better defended when models are more toxic, so increasing costs relaxes selection on mimics (Goodale and Sneddon 1977; Lindström et al. 1997), while mimetic precision in hoverflies appears to increase with their size, suggesting that increased benefits of attacking mimics also can select for better mimicry (Penney et al. 2012). Finally, increasing the availability of alternative prey (and hence the relative dietary importance of mimics) relaxes selection for better mimicry (Lindström et al. 2004).

The widespread support for the relaxed selection hypothesis illustrates its generality across different taxa and types of mimetic relationships. Signal detection problems are pervasive in animal communication (Rowe 1999; Wiley 2006), having also played an important role in discussions of kin recognition (e.g., Reeve 1989) and sexual selection (e.g., Getty 1999). Indeed, as there will always be some error in receivers' sensory systems, there is likely an area of relaxed selection on some phenotypic scale in every system. However, given the large potential risks associated with mistakenly accepting models in some systems, the phenotypic space of nearly neutral selection around model phenotypes can be quite wide.

Many studies that find support for the relaxed selection hypothesis use a single dimension or synthesize multiple dimensions with equal weightings; i.e., they assume that multiple dimensions of phenotype are synthesized into a single continuous metric of mimetic resemblance at some higher level of cognition in the receiver's brain. Considering the importance of this assumption, additional research should be conducted to evaluate its validity. However, there is support for this assumption from damselflies (Iserbyt et al. 2011) and hoverflies (Penney et al. 2012).

\section{MIMETIC BREAKDOWN HYPOTHESIS}

There is empirical evidence for mimetic breakdown. In a coral snake mimicry complex in the southeastern U.S., scarlet kingsnakes occur in both sympatry and allopatry with their coral snake model. In sympatry, mimics are favored by natural selection. In allopatry, however, they suffer increased at tacks from predators (Pfennig et al. 2001, 2007). Genetic analyses indicate that gene flow from sympatry to allopatry explains the occurrence of scarlet kingsnakes in allopatry with their model (Harper and Pfennig 2008). However, morphometric analyses reveal that populations in allopatry have much more red on their dorsum than populations in sympatry, which closely resemble their coral snake model in amount of red (Harper and Pfennig 2008). Thus, despite gene flow from sympatric and allopatric populations, selection has led to a breakdown of the mimetic phenotype.

Another example comes from mimetic butterflies in Africa, where Sheppard (1959) 
showed that imperfect mimics were more common in areas with few models. However, breakdown may not explain imperfect mimicry in species that have mimetic and nonmimetic morphs, as sharp clines between mimics and nonmimics may form along the sympatryallopatry boundary with the model, as occurs in admiral butterflies (Ries and Mullen 2008).

\section{PERCEPTUAL EXPLOITATION HYPOTHESIS}

Empirical support for the perceptual exploitation hypothesis comes from studies of unrewarding orchids that dupe male bees into pollinating them by mimicking the pheromones of female bees. In this system, an exotic ratio of volatile odor compounds leads to a stronger pollination response (Vereecken and Schieslt 2008). This is because male bees prefer females from allopatric populations that have different chemical "dialects," which presumably promotes outbreeding (Vereecken et al. 2007). Sensory exploitation is not limited to olfactory stimuli, however. Benitez-Vieyra et al. (2009) found disruptive selection on the shape of a sexually deceptive orchid that resembles female bees, suggesting perceptual exploitation of male bees' visual preferences as well.

\section{SATYRIC MIMICRY HYPOTHESIS}

The predictions of this hypothesis are not supported by the original dataset of Dittrich et al. (1993) that motivated Howse and Allen (1994) to come up with this hypothesis; the fitness of hoverflies increases monotonically with their resemblance to wasps. Schmidt (1958) and Caley and Schluter (2003) also found monotonic increases in fitness with mimetic precision for butterflies and pufferfish mimics, respectively, which is also inconsistent with the expectation for a local fitness peak for some imperfect mimics.

Although not all of the predictions of Howse and Allen's model (1994) may be supported, the general idea of jamming a predator's sensory system with conflicting information remains intriguing. The satyric mimicry hypothesis connects predator psychology to imperfect mimicry in a mechanistic way. Without a doubt, generalization acts to benefit imperfect mimics (e.g., Schmidt 1958; Ford 1971; Pilecki and O’Donald 1971;
Lindström et al. 1997; Caley and Schluter 2003; Lynn et al. 2005; McGuire et al. 2006; Rowland et al. 2007; Kikuchi and Pfennig 2010a,b; Iserbyt et al. 2011; Ihalainen et al. 2012; Penney et al. 2012). However, no experiment has been explicitly designed to test the effect of signal elements presented in conjunction with novel phenotypic elements. More research is needed on how receivers perceive and process signals, as well as how these processes affect receiver behavior and subsequent signal evolution.

\section{MULTIPLE MODELS HYPOTHESIS}

Empirical tests of, and support for, the multiple-models hypothesis are scanty. On the one hand, Edmunds (1978) observed that ant-mimicking spiders with narrow distributions and a single model were better mimics than a wide-ranging species that overlapped with several models. On the other hand, Penney et al. (2012) did not find any evidence of intermediate phenotypes between different models among poor hoverfly mimics of wasps and bees, suggesting that multiple models have little relevance in that system. This hypothesis remains plausible and awaits further testing.

\section{MULTIPLE PREDATORS HYPOTHESIS}

Pekár et al. (2011) found empirical support for their hypothesis in a study of myrmecomorphic (ant-mimicking) spiders. Many predators display a generalized avoidance of ants, which selects for mimicry, but some predators preferentially attack ants. There appears to be a tradeoff between being a good ant mimic and being able to escape the specialized ant predators quickly, which selects for imperfect mimicry. Because Pekár et al. (2011) examined only a few taxa of imperfect mimics, future studies are needed to determine if a tradeoff between mimetic accuracy and movement speed is consistent across phylogeny. However, this hypothesis is highly persuasive and consistent with empirical measurements. Endler and Mappes (2004) showed that multiple predators may select for weakly conspicuous aposematic signals among defended prey, so the potential implications of multiple predators on the evo- 
lution of mimicry may be more extensive that the current incarnation of this hypothesis implies.

\section{KIN SELECTION HYPOTHESIS}

This hypothesis predicts that inaccurate mimicry will be most likely when models are weakly defended and uncommon, and that it will be more prevalent in species with limited dispersal and high degrees of family grouping (Johnstone 2002). The first prediction is at odds with the predictions of the relaxed selection hypothesis. Therefore, studies of mimetic precision over a range of model abundance that have found that better mimics are favored when models are rare do not support kin selection as a mechanism for maintaining imperfect mimicry (e.g., Harper and Pfennig 2007; Iserbyt et al. 2011; Penney et al. 2012). However, to our knowledge, no study has explicitly measured relatedness within any natural population of mimics.

\section{CHARACTER DISPLACEMENT HYPOTHESIS}

Although empirical tests of the character displacement hypothesis for the evolution of imprecise mimicry are lacking, a growing number of studies have documented reproductive and resource competition among the members of the same mimicry complex (reviewed in Rainey and Grether 2007; Pfennig and Kikuchi 2012). For instance, Müllerian co-mimics may often risk engaging in deleterious reproductive interactions with each other if the same signals used to warn potential predators are also used to attract mates. A recent test of this hypothesis comes from butterfly species of the genus Heliconius, where numerous species have converged on the same wing color patterns, owing to Müllerian mimicry. In this group, not only is wing coloration used to signal unpalatability to potential predators, it is also used to signal to prospective mates, which may increase the risk of costly reproductive interactions between species. Estrada and Jiggins (2008) studied interspecific attraction between two species, Heliconius erato and H. melpomene, and found that both species do indeed spend considerable time approaching and courting females of the co-mimic species. Such mistakes in mate choice may favor reproductive character displacement as a means of reducing these costly reproductive interactions, which could result in imperfect mimicry in some cases.

Resource competition-and possibly ecological character displacement-has also been documented among the members of the same mimicry complex. For example, syntopic Müllerian co-mimics of neotropical catfish differ in resource use (Alexandrou et al. 2011), suggesting scope for resource competition to cause character displacement (and therefore possibly imperfect mimicry) in mimicry complexes.

However, as noted above, for ecological character displacement to promote the evolution of imperfect mimicry, aposematic/mimetic signals aimed at potential predators must be in some way environmentally dependent, such that their production requires some limited resource (e.g., a food item or a particular habitat). Only a handful of studies have examined empirically whether resource competition affects the production of aposematic signals, but the results of these studies suggest that ecological character displacement could promote imperfect mimicry. For example, Blount et al. (2012) found that in seven-spot ladybird beetles (Coccinella septempunctata), which possess both toxins and warning coloration, resource (i.e., food) availability affects both toxin levels and warning coloration. Moreover, many toxic fish species use warning coloration to alert potential predators of their noxiousness (reviewed in Cott 1940; Edmunds 1974), and other species sometimes mimic these colors (e.g., Moland et al. 2005; Alexandrou et al. 2011). Coloration in many species of fish is diet dependent, such that dietary components (e.g., carotenoids) are required for these displays (e.g., Seehausen and van Alphen 1998; Boughman 2001). If ecological character displacement were to cause such species to shift their diet, so that the dietary components used to generate a mimetic signal were no longer available (or were too costly to obtain), then imprecise mimicry may result. 
Tests of Multiple Hypotheses in Single Systems

To determine if one hypothesis (or category of hypotheses) is more crucial than the others in explaining the evolution of mimicry, we need to determine the relative contributions of each hypothesis toward the evolution of imperfect mimicry. The best way to do so is to identify mimicry complexes in which multiple hypotheses can be evaluated simultaneously.

To date, only two mimicry complexes have been subjected to tests aimed at evaluating multiple hypotheses. In one such study, Penney et al. (2012) sought to explain imprecise mimicry of wasps by hoverflies (see above) by testing the eye-of-the-beholder, relaxed selection, kin selection, and multiple model hypotheses. They predicted that there would be a discrepancy between human and avian rankings of model-mimic similarity if the eyeof-the-beholder hypothesis held, and that mimics would fall between models in phenotype if they used more than one model. They also predicted that mimics would decrease in precision with their relative abundance if kin selection affected their populations, but that precision would increase with mimic abundance if the relaxed selection hypothesis were correct. Their tests of these predictions were facilitated by four major factors: multiple populations of models and mimics with different model:mimic abundance ratios; a phylogenetic tree of the mimics to account for phylogenetic signal in mimicry; a large museum dataset from which to obtain morphometric measures of models and mimics; and empirical discrimination data from both likely signal receivers and humans. Their dataset for bird discrimination of hoverflies and wasps is from Dittrich et al. (1993), and they focused their morphometric analyses on traits that a simulation showed to be important for birds' decision-making (Bain et al. 2007). Once they had accounted for phylogenetic signal, their results supported the relaxed selection hypothesis. Results were also consistent with some of the other hypotheses that we have classified as tradeoffs or constraints, but were not designed to discriminate between them.
The second mimicry complex that has been subjected to tests aimed at evaluating multiple hypotheses is a coral snake mimicry complex in the southeastern United States. Early work demonstrated that scarlet kingsnakes were in fact Batesian mimics of coral snakes (Pfennig et al. 2001). Later work showed that imperfect mimicry in the ratio of red:black in the scarlet kingsnake's dorsal rings could be explained by the relaxed selection hypothesis (Harper and Pfennig 2007). Studies also showed that some allopatric scarlet kingsnakes were not mimics, but were in the process of evolving new, less mimetic phenotypes (Harper and Pfennig 2008), thereby supporting the mimetic breakdown hypothesis. Additionally, other studies found that imperfect mimicry in snake dorsal color ring order was not used by predators in discriminating between the deadly model and its mimic (Kikuchi and Pfennig 2010a), supporting the eye-of-the-beholder hypothesis. Therefore, at least three hypotheses-the relaxed selection hypothesis, the mimetic breakdown hypothesis, and the eyeof-the-beholder hypothesis-can explain the apparent occurrence of imperfect mimicry in this system.

More generally, these studies of imperfect mimicry in a coral snake mimicry complex serve to illustrate an important point. Namely, that the 11 hypotheses that we have discussed here are not mutually exclusive, and that multiple explanations may therefore account for the existence of imprecise mimicry in any one system/mimicry complex. The challenge for future empirical work is to determine which, if any, of the hypotheses is more important than the others in promoting the evolution of imperfect mimicry.

\section{Unexplained Phenomena}

Although we have here explored the evidence for 11 existing hypotheses for imperfect mimicry, there are still some phenomena that probably cannot be explained by any of them. Below, we present two such empirical problems that will likely require the development of new theory.

First, consider European vipers and their colubrid mimics. The vipers have at least two components to their aposematic signal: a dark 
dorsal zigzag and a triangular head (Wüster et al. 2004; Niskanen and Mappes 2005; Valkonen et al. 2011). However, colubrid mimics need bear only one of those two signal elements to receive as much protection from predators as vipers do (Valkonen et al. 2011). Predators avoid replica snakes to the same degree whether they have triangular heads, dorsal zigzags, or both. At first glance, this nonadditive interaction between signal components seems reminiscent of the relaxed selection hypothesis (because imperfect mimics are protected as well as perfect mimics). Yet, this example cannot be explained by the relaxed selection hypothesis, because the viper's signal occupies two dimensions of signal space, and imperfect mimics can be completely nonoverlapping with their models in either one of them. The relaxed selection hypothesis depends on partial overlap between models and mimics within a single dimension, so unless multiple components of aposematic signals are combined into one at some level of neural processing, it cannot explain this instance of imperfect mimicry. Therefore, to explain such imprecise mimicry, we need to understand: why multicomponent aposematic signals evolve; and why not all components of aposematic signals are needed to elicit full predator avoidance.

Second, recent data suggest that the complexity of prey communities alters selection for signal mimicry, but no theory consistently anticipates this result. Beatty et al. (2004) conducted a series of experiments that measured human predators as they learned to discriminate between computer-generated profitable and unprofitable prey. They altered the phenotypic variety of both profitable and unprofitable prey, and measured the fitness of imperfect Müllerian mimics depending on whether they shared a single trait (also known as a feature) in common with their models. They found that in simple communities, there was little selection for mimicry at all because humans learned to identify each prey phenotype uniquely. In complex communities, selection favored imperfect mimics that shared a feature with other unprofitable prey. Beatty et al. (2004) interpreted their results as illustrating the difficulty of memorizing multiple prey phenotypes, and suggested that, in general, more complex communities may select for Müllerian mimicry by favoring imperfect mimics.

Ihalainen et al. (2012) revisited this topic and trained birds to forage in communities of artificial prey with varying levels of complexity in the phenotypes of defended and undefended prey. They then tested the responses of the trained birds to a quantitative gradient of signals based on a single aposematic signal that was present in all of the training communities. They found that birds trained in simple communities selected for very precise mimicry, but birds trained in complex ones did not discriminate at all among the gradient of phenotypes presented. They interpreted the difference between their results and those of Beatty et al. (2004) as being at least partially attributable to the behavior of naive and trained predators and suggested that a mixture of naive (coarsely discriminating) and refined (finely discriminating) predators might select for both the initial evolution of mimicry and its improvement.

The use of independent features on the imperfect mimics in Beatty et al. (2004) as opposed to the continuous gradient of phenotypes tested by Ihalainen et al. (2012) complicates direct comparison between the two studies because they might involve different psychological processes. Chittka and Osorio (2007) proposed that predators in complex prey communities might use discrete features of prey to classify them, while Ihalainen et al. (2012) speculated that predators trained on diets of limited variety were less willing to attack unfamiliar prey because they generalized very narrowly (i.e., discriminated within a single continuous dimension of phenotype). In response to the issues raised by these studies, we need to know not only how the number of prey species in a community affects the precision of mimicry, but also take into consideration the experience and variety of predators, and the nature of the phenotypes being evaluated (multicomponent or single dimension, and continuous or discrete variation). 


\section{Conclusions}

We have presented and evaluated the evidence for the major hypotheses for imperfect mimicry. Although only two systems have been subjected to multiple tests, empirical support for individual hypotheses for imperfect mimicry comes from many systems. Particularly, many studies have found results consistent with the predictions of the relaxed selection hypothesis. The eye-of-thebeholder hypothesis is also widely applicable, because it is often difficult to know exactly what aspects of the model's phenotype constitute its signal to receivers. By contrast, mimetic breakdown has only been found in systems with allopatric mimics. Chase-away, perceptual exploitation, and multiple predators have been each supported by one or two studies. That imperfect mimicry is caused by developmental or genetic constraints is difficult to demonstrate, but the shared supergenes of Heliconius indicate a role for phylogeny and hybridization in facilitating the evolution of mimicry. The multiple models and kin selection have not been supported in the study systems where some of their predictions have been tested, and the satyric mimicry and character displacement hypotheses await direct tests.

It is important to stress that some of the hypotheses have been developed from studies that have focused on the natural history of particular systems (e.g., Vereeken and Schiestl 2008; Benitez-Vieyra et al. 2009; Pekár et al. 2011). For this reason, these studies have not tested any alternative hypotheses for imperfect mimicry. Other hypotheses were developed largely from plausible theoretical arguments, but are much more difficult to test than others. Thus, it is premature to rank them in terms of their likely importance in promoting the evolution of imperfect mimicry. Additionally, multiple hypotheses may operate simultaneously in many systems and, together, they may contribute to the evolution of imperfect mimicry.

Ideally, studies of imperfect mimicry should establish that mimicry in fact occurs and identify the aspects of phenotype that constitute the signal (i.e., test the mimetic breakdown and eye-of-the-beholder hypotheses).
The remaining hypotheses that can be tested may be contingent on the details of the study system. Systems that span geographical areas where the model:mimic ratio varies and is easily measured are ideal for testing the relaxed selection hypothesis, as are those where models and mimics vary in the costs and benefits they offer. The presence of multiple models, specialist predators, strong spatial grouping of kin, and likely competition between mimics and their models/co-mimics are prerequisites for testing the multiple model, multiple predators, kin selection, and character displacement hypotheses, respectively. The satyric mimicry hypothesis would have to be evaluated in conditions where the cognitive mechanisms of signal receivers can be directly studied or at least inferred.

In the future, we must gather more information on the fitness consequences of imperfect mimicry in natural populations. Such studies are needed to determine if imprecise mimicry is disfavored, as highly favored as precise mimicry, or even more highly favored than precise mimicry. This information is key to differentiating among the various hypotheses for imprecise mimicry (see Table 1). Given the attention Batesian mimicry complexes have received, greater effort should go into evaluating the various hypotheses for imperfect mimicry in Müllerian mimicry complexes. Fortunately, new cases of mimicry are constantly being discovered (e.g., Brown 2006; Marek and Bond 2009; Wilson et al. 2012). With such a profusion of mimicry complexes, it should become easier to find appropriate study systems in which to address any given hypothesis for imprecise mimicry.

We also need to uncover the proximate mechanisms that generate mimetic phenotypes. Although a number of recent studies have shown promise in this area (e.g., see Reed et al. 2011; Kikuchi and Pfennig 2012b), we still know virtually nothing about the proximate mechanisms by which mimetic phenotypes are produced and, hence, whether or not genetic or developmental constraints play a role in explaining the persistence of imperfect mimics. To resolve the unexplained phenomena in imperfect mimicry that we introduced above, theories of 
optimal decision-making and cognitive psychology may be helpful (e.g., Rowe 1999; Darst 2006; Sherratt 2011). We urgently require empirical work to challenge and improve theory (e.g., Hansen et al. 2010; Rowland et al. 2010). Directly measuring animal decision-making (e.g., Alatalo and Mappes 1996) and incorporating physiology and neurobiology into perceptual models can produce dramatic advances in our ability to explain how animals see and evaluate the world. Finally, recognizing that mimicry occurs within complex communities of prey must also be a major thrust of future research.
Such studies are important because the existence of imperfect mimicry represents a key challenge to mimicry theory (Ruxton et al. 2004). More generally, clarifying why imperfect mimicry exists promises to provide critical insights into the limits of natural selection in producing complex adaptations.

\section{ACKNOWLEDGMENTS}

Our work has been supported by NSF grants DEB1110385 and DEB-1019479 and the Royster Society of Fellows at UNC-Chapel Hill. We would like to thank two anonymous reviewers for helpful comments.

\section{REFERENCES}

Alatalo R. V., Mappes J. 1996. Tracking the evolution of warning signals. Nature 382:708-710.

Alexandrou M. A., Oliveira C., Maillard M., McGill R. A. R., Newton J., Creer S., Taylor M. I. 2011. Competition and phylogeny determine community structure in Müllerian co-mimics. Nature 469:84-88.

Bain R. S., Rashed A., Cowper V. J., Gilbert F. S., Sherratt T. N. 2007. The key mimetic features of hoverflies through avian eyes. Proceedings of the Royal Society of London Series B: Biological Sciences 274:1949-1954.

Basolo A. L. 1990. Female preference predates the evolution of the sword in swordtail fish. Science 250:808-810.

Bates H. W. 1862. Contributions to an insect fauna of the Amazon valley (Lepidoptera: Heliconidae). Transactions of the Linnean Society of London 23:495-566.

Beatty C. D., Franks D. W. 2012. Discriminative predation: simultaneous and sequential encounter experiments. Current Zoology 58:649-657.

Beatty C. D., Beirinckx K., Sherratt T. N. 2004. The evolution of Müllerian mimicry in multispecies communities. Nature 431:63-67.

Benitez-Vieyra S., Medina A. M., Cocucci A. A. 2009. Variable selection patterns on the labellum shape of Geoblasta pennicillata, a sexually deceptive orchid. Journal of Evolutionary Biology 22:2354-2362.

Blount J. D., Rowland H. M., Drijfhout F. P., Endler J. A., Inger R., Sloggett J. J., Hurst G. D. D., Hodgson D. J., Speed M. P. 2012. How the ladybird got its spots: effects of resource limitation on the honesty of aposematic signals. Functional Ecology 26: 334-342.

Boughman J. W. 2001. Divergent sexual selection enhances reproductive isolation in sticklebacks. Nature 411:944-948.

Bradbury J. W., Vehrencamp S. L. 2011. Principles of Animal Communication. Sunderland (Massachusetts): Sinauer Associates.
Brodie E. D. III, Brodie E. D. Jr. 2004. Venomous snake mimicry. Pages 617-633 in The Venomous Reptiles of the Western Hemisphere, Volume 2, edited by J. A. Campbell and W. W. Lamar. Ithaca (New York): Cornell University Press.

Brower J. V. 1960. Experimental studies of mimicry. IV. The reactions of starlings to different proportions of models and mimics. American Naturalist 94:271-282.

Brown R. M. 2006. A case of suspected coral snake (Hemibungarus calligaster) mimicry by lepidopteran larvae (Bracca sp.) from Luzon Island, Philippines. Raffles Bulletin of Zoology 54:225-227.

Brown W. L. Jr., Wilson E. O. 1956. Character displacement. Systematic Zoology 5:49-64.

Caley M. J., Schluter D. 2003. Predators favour mimicry in a tropical reef fish. Proceedings of the Royal Society of London Series B: Biological Sciences 270:667-672.

Chittka L., Osorio D. 2007. Cognitive dimensions of predator responses to imperfect mimicry? PLOS Biology 5:e339.

Cott H. B. 1940. Adaptive Colouration in Animals. London (United Kingdom): Methuen.

Cuthill I. C., Bennett A. T. D. 1993. Mimicry and the eye of the beholder. Proceedings of the Royal Society of London Series B: Biological Sciences 253:203-204.

Darst C. R. 2006. Predator learning, experimental psychology and novel predictions for mimicry dynamics. Animal Behaviour 71:743-748.

Dayan T., Simberloff D. 2005. Ecological and communitywide character displacement: the next generation. Ecology Letters 8:875-894.

Dill L. M. 1975. Calculated risk-taking by predators as a factor in Batesian mimicry. Canadian Journal of Zoology-Revue Canadienne De Zoologie 53:1614-1621.

Dittrich W., Gilbert F., Green P., McGregor P., Grewcock D. 1993. Imperfect mimicry: a pigeon's per- 
spective. Proceedings of the Royal Society of London Series B: Biological Sciences 251:195-200.

Duncan C. J., Sheppard P. M. 1965. Sensory discrimination and its role in the evolution of Batesian mimicry. Behaviour 24:269-282.

Edmunds M. 1974. Defence in Animals: A Survey of Anti-Predator Defences. Burnt Mill (United Kingdom): Longman.

Edmunds M. 1978. On the association between Myrmarachne spp. (Salticidae) and ants. Bulletin of the British Arachnological Society 4:149-160.

Edmunds M. 2000. Why are there good and poor mimics? Biological Journal of the Linnean Society 70: 459-466.

Endler J. A. 1981. An overview of the relationships between mimicry and crypsis. Biological Journal of the Linnean Society 16:25-31.

Endler J. A., Mappes J. 2004. Predator mixes and the conspicuousness of aposematic signals. American Naturalist 163:532-547.

Estrada C., Jiggins C. D. 2008. Interspecific sexual attraction because of convergence in warning colouration: is there a conflict between natural and sexual selection in mimetic species? Journal of Evolutionary Biology 21:749-760.

Forbes P. 2009. Dazzled and Deceived: Mimicry and Camouflage. New Haven (Connecticut): Yale University Press.

Ford E. B. 1953. The genetics of polymorphism in the Lepidoptera. Advances in Genetics 5:43-87.

Ford H. A. 1971. The degree of mimetic protection gained by new partial mimics. Heredity 27:227-236.

Franks D. W., Noble J. 2004. Batesian mimics influence mimicry ring evolution. Proceedings of the Royal Society of London Series B: Biological Sciences 271:191-196.

Franks D. W., Ruxton G. D., Sherratt T. N. 2009. Warning signals evolve to disengage Batesian mimics. Evolution 63:256-267.

Getty T. 1985. Discriminability and the sigmoid functional response: how optimal foragers could stabilize model-mimic complexes. American Naturalist 125:239-256.

Getty T. 1999. Chase-away sexual selection as noisy reliable signaling. Evolution 53:299-302.

Gilbert F. 2005. The evolution of imperfect mimicry. Pages 231-288 in Insect Evolutionary Ecology, edited by M. D. E. Fellows, G. J. Holloway, and J. Rolff. Wallingford (United Kingdom): CABI Publishing.

Goodale M. A., Sneddon I. 1977. The effect of distastefulness of the model on the predation of artificial Batesian mimics. Animal Behaviour 25:660-665.

Grant P. R. 1972. Convergent and divergent character displacement. Biological Journal of the Linnean Society 4:39-68.

Greene H. W., McDiarmid R. W. 2005. Wallace and Savage: heroes, theories and venomous snake mimicry. Pages 190-208 Ecology and Evolution in the Tropics: A Herpetological Perspective, edited by M. A. Donnelly, B. I. Crother, C. Guyer, M. H. Wake, and M. E. White. Chicago (Illinois): University of Chicago Press.

Grether G. F., Losin N., Anderson C. N., Okamoto K. 2009. The role of interspecific interference competition in character displacement and the evolution of competitor recognition. Biological Reviews 84:617-635.

Grim T. 2013. Perspectives and debates: mimicry, signalling and co-evolution (commentary on Wolfgang Wickler-understanding mimicry—with special reference to vocal mimicry). Ethology 119:270-277.

Hansen B. T., Holen Ø. H., Mappes J. 2010. Predators use environmental cues to discriminate between prey. Behavioral Ecology and Sociobiology 64:1991-1997.

Harper G. R. Jr., Pfennig D. W. 2007. Mimicry on the edge: why do mimics vary in resemblance to their model in different parts of their geographical range? Proceedings of the Royal Society of London Series B: Biological Sciences 274:1955-1961.

Harper G. R. Jr., Pfennig D. W. 2008. Selection overrides gene flow to break down maladaptive mimicry. Nature 451:1103-1106.

Heliconius Genome Consortium. 2012. Butterfly genome reveals promiscuous exchange of mimicry adaptations among species. Nature 487:94-98.

Holen Ø. H., Johnstone R. A. 2004. The evolution of mimicry under constraints. American Naturalist 164:598-613.

Holland B., Rice W. R. 1998. Perspective: chase-away sexual selection: antagonistic seduction versus resistance. Evolution 52:1-7.

Holmgren N. M. A., Enquist M. 1999. Dynamics of mimicry evolution. Biological Journal of the Linnean Society 66:145-158.

Howse P. E., Allen J. A. 1994. Satyric mimicry: the evolution of apparent imperfection. Proceedings of the Royal Society of London Series B: Biological Sciences 257:111-114.

Ihalainen E., Rowland H. M., Speed M. P., Ruxton G. D., Mappes J. 2012. Prey community structure affects how predators select for Müllerian mimicry. Proceedings of the Royal Society of London Series B. Biological Sciences 279:2099-2105.

Iserbyt A., Bots J., Van Dongen S., Ting J. J., Van Gossum H., Sherratt T. N. 2011. Frequency-dependent variation in mimetic fidelity in an intraspecific mimicry system. Proceedings of the Royal Society of London Series B: Biological Sciences 278:3116-3122.

Johnstone R. A. 2002. The evolution of inaccurate mimics. Nature 418:524-526.

Joron M., Frezal L., Jones R. T., Chamberlain N. L., Lee S. F., Haag C. R., Whibley A., Becuwe M., Baxter S. W., Ferguson L., Wilkinson P. A., Salazar C., Davidson C., Clark R., Quail M. A., Beasley H., Glithero R., Lloyd C., Sims S., Jones M. C., Rogers 
J., Jiggins C. D., Ffrench-Constant R. H. 2011. Chromosomal rearrangements maintain a polymorphic supergene controlling butterfly mimicry. Nature 477:203-206.

Kikuchi D. W., Pfennig D. W. 2010a. Predator cognition permits imperfect coral snake mimicry. American Naturalist 176:830-834.

Kikuchi D. W., Pfennig D. W. 2010b. High-model abundance may permit the gradual evolution of Batesian mimicry: an experimental test. Proceedings of the Royal Society of London Series B: Biological Sciences 277:10411048.

Kikuchi D. W., Pfennig D. W. 2012a. Mimicry. In Oxford Bibliographies Online: Ecology, edited by D. Gibson. New York: Oxford University Press. doi: 10.1093/OBO/9780199830060-0027.

Kikuchi D. W., Pfennig D. W. 2012b. A Batesian mimic and its model share color production mechanisms. Current Zoology 58:658-667.

Lindström L., Alatalo R. V., Mappes J. 1997. Imperfect Batesian mimicry-the effects of the frequency and the distastefulness of the model. Proceedings of the Royal Society of London Series B: Biological Sciences 264:149-153.

Lindström L., Alatalo R. V., Lyytinen A., Mappes J. 2004. The effect of alternative prey on the dynamics of imperfect Batesian and Müllerian mimicries. Evolution 58:1294-1302.

Lynn S. K., Cnaani J., Papaj D. R. 2005. Peak shift discrimination learning as a mechanism of signal evolution. Evolution 59:1300-1305.

Malcolm S. B. 1990. Mimicry: status of a classical evolutionary paradigm. Trends in Ecology and Evolution 5:57-62.

Mallet J., Joron M. 1999. Evolution of diversity in warning color and mimicry: polymorphisms, shifting balance, and speciation. Annual Review of Ecology and Systematics 30:201-233.

Marek P. E., Bond J. E. 2009. A Müllerian mimicry ring in Appalachian millipedes. Proceedings of the National Academy of Sciences of the United States of America 106:9755-9760.

Martin A., Papa R., Nadeau N. J., Hill R. I., Counterman B. A., Halder G., Jiggins C. D., Kronforst M. R., Long A. D., McMillan W. O., Reed R. D. 2012. Diversification of complex butterfly wing patterns by repeated regulatory evolution of a Wnt ligand. Proceedings of the National Academy of Sciences of the United States of America 109:12632-12637.

Maynard Smith J., Harper D. 2003. Animal Signals. Oxford (United Kingdom): Oxford University Press.

Maynard Smith J., Burian R., Kauffman S., Alberch P., Campbell J., Goodwin B., Lande R., Raup D., Wolpert L. 1985. Developmental constraints and evolution: a perspective from the Mountain Lake Conference on Development and Evolution. Quarterly Review of Biology 60:265-287.
McGuire L., Van Gossum H., Beirinckx K., Sherratt T. N. 2006. An empirical test of signal detection theory as it applies to Batesian mimicry. Behavioural Processes 73:299-307.

Moland E., Eagle J. V., Jones G. P. 2005. Ecology and evolution of mimicry in coral reef fishes. Pages 455-482 in Oceanography and Marine Biology: An Annual Review, Volume 43, edited by R. N. Gibson, R. J. A. Atkinson, and J. D. M. Gordon. Boca Raton (Florida): CRC Press (Taylor \& Francis Group).

Müller F. 1879. Ituna and Thyridia: a remarkable case of mimicry in butterflies. Transactions of the Entomological Society of London 1879:xx-xxix.

Niskanen M., Mappes J. 2005. Significance of the dorsal zigzag pattern of Vipera latastei gaditana against avian predators. Journal of Animal Ecology 74: 1091-1101.

Nur U. 1970. Evolutionary rates of models and mimics in Batesian mimicry. American Naturalist 104:477486.

Oaten A., Pearce C. E. M., Smyth M. E. B. 1975. Batesian mimicry and signal detection theory. Bulletin of Mathematical Biology 37:367-387.

Pekár S., Jarab M., Fromhage L., Herberstein M. E. 2011. Is the evolution of inaccurate mimicry a result of selection by a suite of predators? A case study using myrmecomorphic spiders. American Naturalist 178:124-134.

Penney H. D., Hassall C., Skevington J. H., Abbott K. R., Sherratt T. N. 2012. A comparative analysis of the evolution of imperfect mimicry. Nature 483 : 461-464.

Pfennig D. W., Kikuchi D. W. 2012. Competition and the evolution of imperfect mimicry. Current Zoology 58:608-619.

Pfennig D. W., Mullen S. P. 2010. Mimics without models: causes and consequences of allopatry in Batesian mimicry complexes. Proceedings of the Royal Society of London Series B: Biological Sciences 277:25772585.

Pfennig D. W., Pfennig K. S. 2012. Evolution's Wedge: Competition and the Origins of Diversity. Berkeley (California): University of California Press.

Pfennig K. S., Pfennig D. W. 2009. Character displacement: ecological and reproductive responses to a common evolutionary problem. Quarterly Review of Biology 84:253-276.

Pfennig D. W., Harcombe W. R., Pfennig K. S. 2001. Frequency-dependent Batesian mimicry. Nature 410:323-323.

Pfennig D. W., Harper G. R. Jr., Brumo A. F., Harcombe W. R., Pfennig K. S. 2007. Population differences in predation on Batesian mimics in allopatry with their model: selection against mimics is strongest when they are common. Behavioral Ecology and Sociobiology 61:505-511.

Pilecki C., O'Donald P. 1971. The effects of predation 
on artificial mimetic polymorphisms with perfect and imperfect mimics at varying frequencies. Evolution 25:365-370.

Pough F. H. 1976. Multiple cryptic effects of crossbanded and ringed patterns of snakes. Copeia 1976:834-836.

Rainey M. M., Grether G. F. 2007. Competitive mimicry: synthesis of a neglected class of mimetic relationships. Ecology 88:2440-2448.

Reed R. D., Papa R., Martin A., Hines H. M., Counterman B. A., Pardo-Diaz C., Jiggins C. D., Chamberlain N. L., Kronforst M. R., Chen R., Halder G., Nijhout H. F., McMillan W. O. 2011. optix drives the repeated convergent evolution of butterfly wing pattern mimicry. Science 333:1137-1141.

Reeve H. K. 1989. The evolution of conspecific acceptance thresholds. American Naturalist 133:407-435.

Ries L., Mullen S. P. 2008. A rare model limits the distribution of its more common mimic: a twist on frequency-dependent Batesian mimicry. Evolution 62:1798-1803.

Rowe C. 1999. Receiver psychology and the evolution of multicomponent signals. Animal Behaviour 58: 921-931.

Rowland H. M., Ihalainen E., Lindström L., Mappes J., Speed M. P. 2007. Co-mimics have a mutualistic relationship despite unequal defences. Nature 448: 64-67.

Rowland H. M., Hoogesteger T., Ruxton G. D., Speed M. P., Mappes J. 2010. A tale of 2 signals: signal mimicry between aposematic species enhances predator avoidance learning. Behavioral Ecology 21: 851-860.

Ruxton G. D., Sherratt T. N., Speed M. P. 2004. Avoiding Attack: The Evolutionary Ecology of Crypsis, Warning Signals, and Mimicry. Oxford (United Kingdom): $\mathrm{Ox}-$ ford University Press.

Ryan M. J., Fox J. H., Wilczynski W., Rand A. S. 1990. Sexual selection for sensory exploitation in the frog Physalaemus pustulosus. Nature 343:66-67.

Savage J. M., Slowinski J. B. 1992. The colouration of the venomous coral snakes (family Elapidae) and their mimics (families Aniliidae and Colubridae). Biological Journal of the Linnean Society 45:235-254.

Schluter D. 2000. Ecological character displacement in adaptive radiation. American Naturalist 156:S4S16.

Schlüter P. M., Xu S., Gagliardini V., Whittle E., Shanklin J., Grossniklaus U., Schiestl F. P. 2011. Stearoyl-acyl carrier protein desaturases are associated with floral isolation in sexually deceptive orchids. Proceedings of the National Academy of Sciences of the United States of America 108:5696-5701.

Schmidt R. S. 1958. Behavioural evidence on the evolution of Batesian mimicry. Animal Behaviour 6:129138.

Seehausen O., van Alphen J. J. M. 1998. The effect of male coloration on female mate choice in closely related Lake Victoria cichlids (Haplochromis nyererei complex). Behavioral Ecology and Sociobiology 42:1-8.

Servedio M. R., Lande R. 2003. Coevolution of an avian host and its parasitic cuckoo. Evolution 57: 1164-1175.

Sheppard P. M. 1959. The evolution of mimicry: a problem in ecology and genetics. Cold Spring Harbor Symposia on Quantitative Biology 24:131-140.

Sherratt T. N. 2001. The evolution of female-limited polymorphisms in damselflies: a signal detection model. Ecology Letters 4:22-29.

Sherratt T. N. 2002. The evolution of imperfect mimicry. Behavioral Ecology 13:821-826.

Sherratt T. N. 2011. The optimal sampling strategy for unfamiliar prey. Evolution 65:2014-2025.

Sherratt T. N., Beatty C. D. 2003. The evolution of warning signals as reliable indicators of prey defense. American Naturalist 162:377-389.

Valkonen J. K., Nokelainen O., Mappes J. 2011. Antipredatory function of head shape for vipers and their mimics. PLOS One 6:e22272.

Vane-Wright R. I. 1976. A unified classification of mimetic resemblances. Biological Journal of the Linnean Society 8:25-56.

Vereecken N. J., Schiestl F. P. 2008. The evolution of imperfect floral mimicry. Proceedings of the National Academy of Sciences of the United States of America 105:7484-7488.

Vereecken N. J., Mant J., Schiestl F. P. 2007. Population differentiation in female sex pheromone and male preferences in a solitary bee. Behavioral Ecology and Sociobiology 61:811-821.

Waldbauer G. P. 1988. Aposematism and Batesian mimicry: measuring mimetic advantage in natural habitats. Evolutionary Biology 22:227-259.

Wickler W. 1968. Mimicry in Plants and Animals. London (United Kingdom): World University Press.

Wiley R. H. 2006. Signal detection and animal communication. Pages 217-247 in Advances in the Study of Behavior, Volume 36, edited by H. J. Brockmann, P. J. B. Slater, C. T. Snowdon, T. J. Roper, M. Naguib, and K. E. Wynne-Edwards. San Diego (California): Elsevier Academic Press.

Wilson J. S., Williams K. A., Forister M. L., von Dohlen C. D., Pitts J. P. 2012. Repeated evolution in overlapping mimicry rings among North American velvet ants. Nature Communications 3:1272.

Wüster W., Allum C. S. E., Bjargardóttir I. B., Bailey K. L., Dawson K. J., Guenioui J., Lewis J., McGurk J., Moore A. G., Niskanen M., Pollard C. P. 2004. Do aposematism and Batesian mimicry require bright colours? A test, using European viper markings. Proceedings of the Royal Society of London Series B: Biological Sciences 271:2495-2499.

Handling Editor: Daniel Dykhuizen 